\title{
CVD Graphene/Ni Interface Evolution in Sulfuric Electrolyte
}

\author{
Rossella Yivlialin, ${ }^{\dagger}$ Gianlorenzo Bussetti, ${ }^{* \dagger \dagger}{ }^{\dagger}$ Lamberto Duò, ${ }^{\dagger}$ Feng Yu, ${ }^{\dagger}$ Miriam Galbiati, ${ }^{\dagger}$ \\ and Luca Camilli \\ ${ }^{\dagger}$ Department of Physics, Politecnico di Milano, p.za Leonardo da Vinci 32, I-20133 Milano, Italy \\ ${ }^{\ddagger}$ Department of Micro- and Nanotechnology, Technical University of Denmark, Ørsteds Plads, 2800 Kgs, Lyngby, Denmark
}

\begin{abstract}
Systems comprising single and multilayer graphene deposited on metals and immersed in acid environments have been investigated, with the aim of elucidating the mechanisms involved, for instance, in hydrogen production or metal protection from corrosion. In this work, a relevant system, namely chemical vapor deposited (CVD) multilayer graphene/Ni (MLGr/Ni), is studied when immersed in a diluted sulfuric electrolyte. The MLGr/Ni electrochemical and morphological properties are studied in situ and interpreted in light of the highly oriented pyrolytic graphite (HOPG) electrode behavior, when immersed in the same electrolyte. Following this interpretative framework, the dominant role of the Ni substrate in hydrogen production is clarified.
\end{abstract}

\section{INTRODUCTION}

The graphene $(\mathrm{Gr}) /$ nickel interface has been the subject of an intense research for the past few years. ${ }^{1-7}$ From a fundamental point of view, $\mathrm{Gr}$ on Ni represents both a prototypical example of graphene with a strongly interacting metal and a significant case of lattice matched system. ${ }^{8}$ On the other hand, concerning applications, this system has been used as a test-bed for evaluating the performance of graphene-based protective coatings. $^{9-12}$ Moreover, $\mathrm{Gr} / \mathrm{Ni}$ is of great interest in energy applications. In this respect, density functional theory calculations have recently shown that the $\mathrm{H}_{2}$ evolution reaction (HER) rate of Gr-coated $\mathrm{Ni}$ is significantly higher than that of bare $\mathrm{Ni}$, and comparable to that of $\mathrm{Pt}^{13}$ If experimentally confirmed, these findings could pave the way for a promising approach to efficiently produce $\mathrm{H}_{2}$, without the need of using expensive Pt catalyst.

All these investigations concern (i) the $\mathrm{Gr} / \mathrm{Ni}$ interface properties and (ii) its changes due to the environment. As the environment strongly affects the system interfacial properties, many studies were performed in controlled ambient (e.g., ultrahigh vacuum $){ }^{8}$ However, there is an urgent request of testing device prototypes in more realistic, application-oriented environments, as for instance in acid liquids [e.g., sulfuric acid $\left.\left(\mathrm{H}_{2} \mathrm{SO}_{4}\right)\right] .{ }^{14}$ The $\mathrm{Gr} / \mathrm{Ni}$ interface represents even in this case a prototypical system, where redox reactions and surface changes can be studied with different electrochemical and microscopic techniques and the results compared with data obtained in controlled environments. More specifically, the $\mathrm{Gr} / \mathrm{Ni}$ electrochemical behavior in both oxidative and HER regimes can be investigated for metal protection and $\mathrm{H}_{2}$ production, respectively.

In this work, aimed by the interest of clarifying the morphological and electrochemical evolution of the $\mathrm{Gr} / \mathrm{Ni}$ interface in acid media (here, $\mathrm{H}_{2} \mathrm{SO}_{4} 0.5 \mathrm{M}$ ), we carry out an investigation of this system through a complementary approach based on cyclic voltammetry (CV) and in situ electrochemical atomic force microscopy (EC-AFM). In particular, to gain insight into the electrochemical behavior of the $\mathrm{Gr} / \mathrm{Ni}$ system, we compare results acquired from (i) highly oriented pyrolytic graphite (HOPG, considered as an ideal graphene multilayer system), (ii) bare $\mathrm{Ni}$, and (iii) chemical vapor deposited (CVD) multilayer (ML) Gr/Ni samples of different thickness.

Our findings show a key role of the buried $\mathrm{Ni}$ electrode, which is wet when the electrode is immersed inside the electrolyte, despite the presence of the MLGr coating. The latter can be interpreted as a HOPG electrode rich of crannies, where ions in solution can pass through and reach the underneath substrate. This model simplifies the interpretation of experimental data and enables the prediction of $\mathrm{MLGr} / \mathrm{Ni}$ electrode behavior in different acid or alkaline electrolytes, such as perchloric acid, Li-based solutions, and so forth.

\section{RESULTS AND DISCUSSION}

The HOPG electrode properties, when immersed in diluted sulfuric acid, have been widely investigated. ${ }^{15-24}$ In Figure 1, we report a traditional $\mathrm{CV}$ from cathodic to anodic EC regions where the Faradaic current, flowing through the HOPG electrode, is measured as a function of the applied EC potential referred to the standard hydrogen electrode (SHE).

The current enhancement above $1.70 \mathrm{~V}$ (anodic regime) is due to oxygen evolution. ${ }^{24}$ The shoulder at $2.03 \mathrm{~V}$ is related to anion intercalation inside the graphite stratified structure. ${ }^{24}$ From a morphological point of view, when the intercalation 


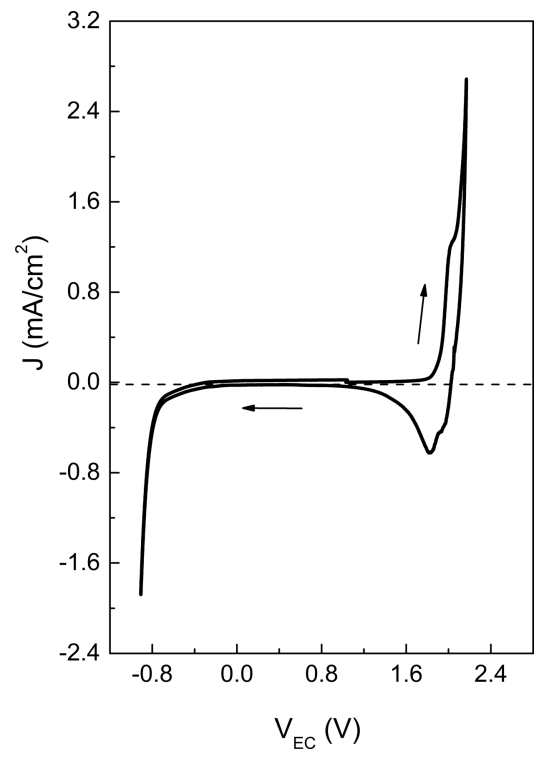

Figure 1. Voltammogram obtained by $\mathrm{CV}$ on $\mathrm{HOPG}$ in $0.5 \mathrm{M} \mathrm{H}_{2} \mathrm{SO}_{4}$. The EC potential is referred to the SHE. The scan rate is $25 \mathrm{mV} / \mathrm{s}$.

stage is reached during the CV, graphite is affected by both carbon detriment and a particular surface swelling known as blisters, which affects and characterizes the overall electrode surface at the submicrometer scale. ${ }^{18,21,22}$ At the intercalation EC potential, $\mathrm{O}_{2}, \mathrm{CO}$ and $\mathrm{CO}_{2}$ gases evolve from both the surface and the underneath graphite layers. In the latter case, gases result trapped below the graphite surface and, unable to escape, swell the sample. In Figure 1, we note the presence of a negative feature between 1.6 and $2.0 \mathrm{~V}$ that is traditionally interpreted in terms of a partial deintercalation process occurring on the electrode. ${ }^{15,22}$ If the EC potential is set below $-0.40 \mathrm{~V}$, the hydrogen production enhances the Faradaic current toward negative values (cathodic regime), in agreement with the Pourbaix diagram. ${ }^{25}$ Interestingly, we note that, when used as a cathode, the HOPG is morphologically stable, even when quite high negative EC potentials are applied on the sample. In particular, no blisters have been observed within the HOPG electrode at negative EC potentials, since hydrogen evolution occurs prior to intercalation, in agreement with reports found in literature. ${ }^{26}$ For this reason, in Figure 2, we compare the significant morphological differences between HOPG in the cathodic (panel a) and anodic (panel b) region.
The former is almost indiscernible with respect to the pristine HOPG sample (panel c).

The electrochemical analysis of $\mathrm{Ni}$ immersed in the diluted sulfuric electrolyte reveals $\mathrm{H}_{2}$ production when the EC potential is lower than $-0.23 \mathrm{~V}$ (see Figure 3 ). ${ }^{27}$ The positive

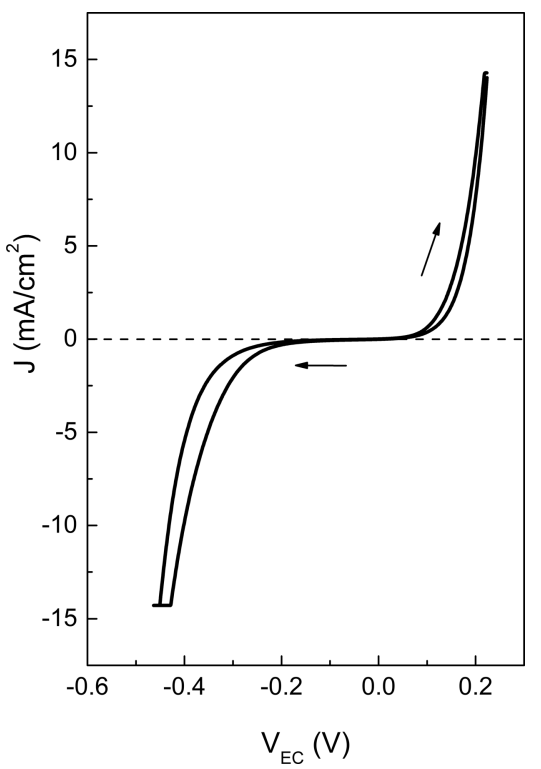

Figure 3. Voltammogram obtained by $\mathrm{CV}$ on bare $\mathrm{Ni}$ in $0.5 \mathrm{M} \mathrm{H}_{2} \mathrm{SO}_{4}$; scan rate $=25 \mathrm{mV} / \mathrm{s}$.

current enhancement above $0.10 \mathrm{~V}$ is in agreement with the literature, ${ }^{25}$ while a detailed analysis of a more anodic region $\left(V_{\mathrm{EC}}>0.2 \mathrm{~V}\right)$ is precluded due to the high current intensity value measured during the experiment, which saturates the high-sensitive ammeter.

At the sub-millimeter scale, we observe some bubbles on the electrode surface acquired by an in situ optical microscopy (see Figure 4), as soon as a single potential sweep is completed. We interpret these bubbles as likely due to hydrogen. ${ }^{25,27}$ The lack of hydrogen bubbles on the HOPG surface is reasonable, due to the different degree of EC activity between graphite and $\mathrm{Ni}$. Referring to the CVs in Figures 1 and 3, respectively, the faradaic current intensity is more than an order of magnitude larger when measured on the metal electrode compared to the HOPG one.
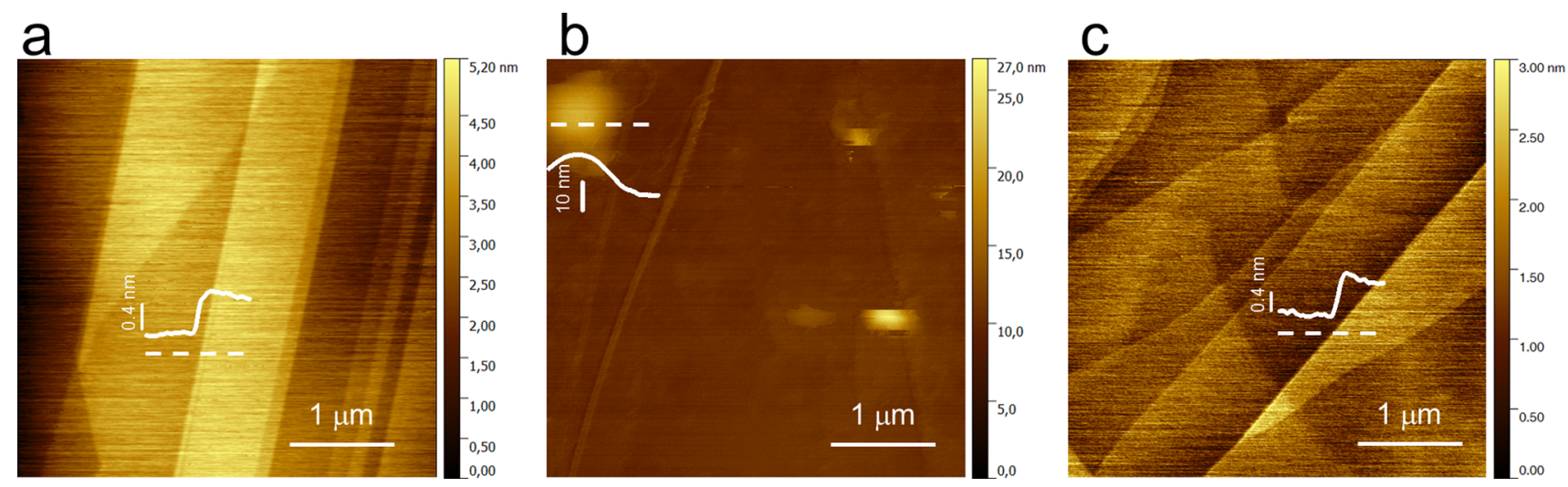

Figure 2. EC-AFM topography $\left(4 \times 4 \mu \mathrm{m}^{2}\right)$ in situ of HOPG in $0.5 \mathrm{M} \mathrm{H}_{2} \mathrm{SO}_{4}$ (a) after CV in the negative (cathodic) EC potential range, (b) after $\mathrm{CV}$ in the positive (anodic) EC potential range, where a characteristic blister affect the surface, and (c) before the CV sweep. 


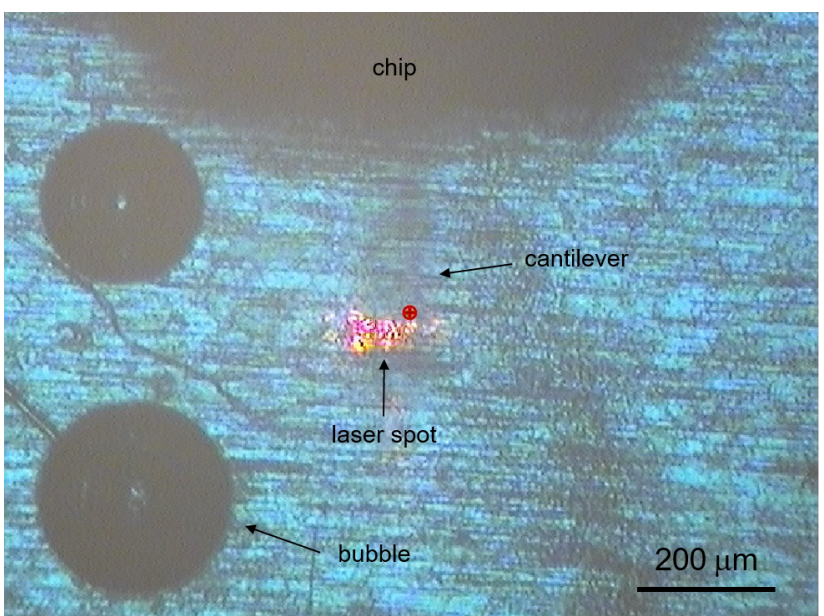

Figure 4. In situ optical microscope image of the bare Ni surface, after $\mathrm{CV}$ in $0.5 \mathrm{M} \mathrm{H}_{2} \mathrm{SO}_{4}$ (see Figure 3).

After these preliminary investigations, a fresh $\mathrm{Ni}$ electrode was coated by a MLGr film, having a nominal thickness of 100 $\mathrm{nm}$. The quality of the Gr overlayer was checked by both Raman spectroscopy (see Figure 5a), where the defect-related $\mathrm{D}$ peak is vanishingly small, ${ }^{28}$ and AFM analysis (see Figure $5 \mathrm{~b})$, where wide areas of flat MLGr are spaced out by clear wrinkles. $^{29,30}$

This sample is used as a working electrode (WE) in our EC cell. In Figure 6, we report the CV collected during a wide EC potential sweep.

In Figure 6a, it is shown that the Faradaic current starts increasing at a lower EC potential with respect to the HOPG electrode (Figure 1). Going from lower to higher potential values, a shoulder appears in the line shape at $1.6 \mathrm{~V}$, which recalls the well-known intercalation stage observed in Figure 1.
We note that, reducing the applied potential, the Faradaic current is always positive, conversely to what measured on the HOPG electrode (see the cathodic feature of Figure 1). This indicates that, during the positive potential sweep, the $\mathrm{Ni}$ substrate is reached by the solvated anions in solution. Reasonably then, it is the high EC activity of Ni that maintains positive the EC current of the MLGr/Ni system, even during the reverse potential sweep.

Considering the cathodic region (Figure $6 \mathrm{~b}$ ), the voltammogram is characterized by a wide feature in the -0.2 to $0.8 \mathrm{~V}$ potential range. This structure is not observed on the HOPG electrode (Figure 1), while the Ni electrode shows a significant current enhancement in the same energy region (Figure 3), as previously commented. Such differences indicate that the $\mathrm{MLGr} / \mathrm{Ni}$ surface is electrochemically more reactive than that of HOPG. We speculate that such reactivity is driven by processes occurring at the buried interface. The MLGr coating is not sufficiently uniform and the anions in solution pass through it eventually reaching the $\mathrm{Ni}$ surface, where they undergo electrochemical reactions. Since the defect-related D peak is vanishingly small in the MLGr Raman spectra (Figure $5 a$ ), the many wrinkles on the surface (Figure 5b) as well as possible grain boundaries (i.e., fractures and/or discontinuities) in the coating film have to be considered as the main responsible for the higher reactivity of the $\mathrm{MLGr} / \mathrm{Ni}$ electrode with respect to HOPG, in agreement with previous interpretations. ${ }^{4,31-33}$ In particular, Deng and Berry suggested that wrinkles give rise to (i) nanosized channels through which gases and molecules can pass through (perfect and flat graphene is instead completely impermeable to all molecules, even hydrogen and helium $)^{34}$ and (ii) a curved, hence more chemically reactive graphene lattice. ${ }^{31}$ Looking at our microscopic data, where wrinkles are the main morphological features characterizing the images, we tend more to this interpretative model instead of a crucial role of grain boundaries. ${ }^{4}$ The

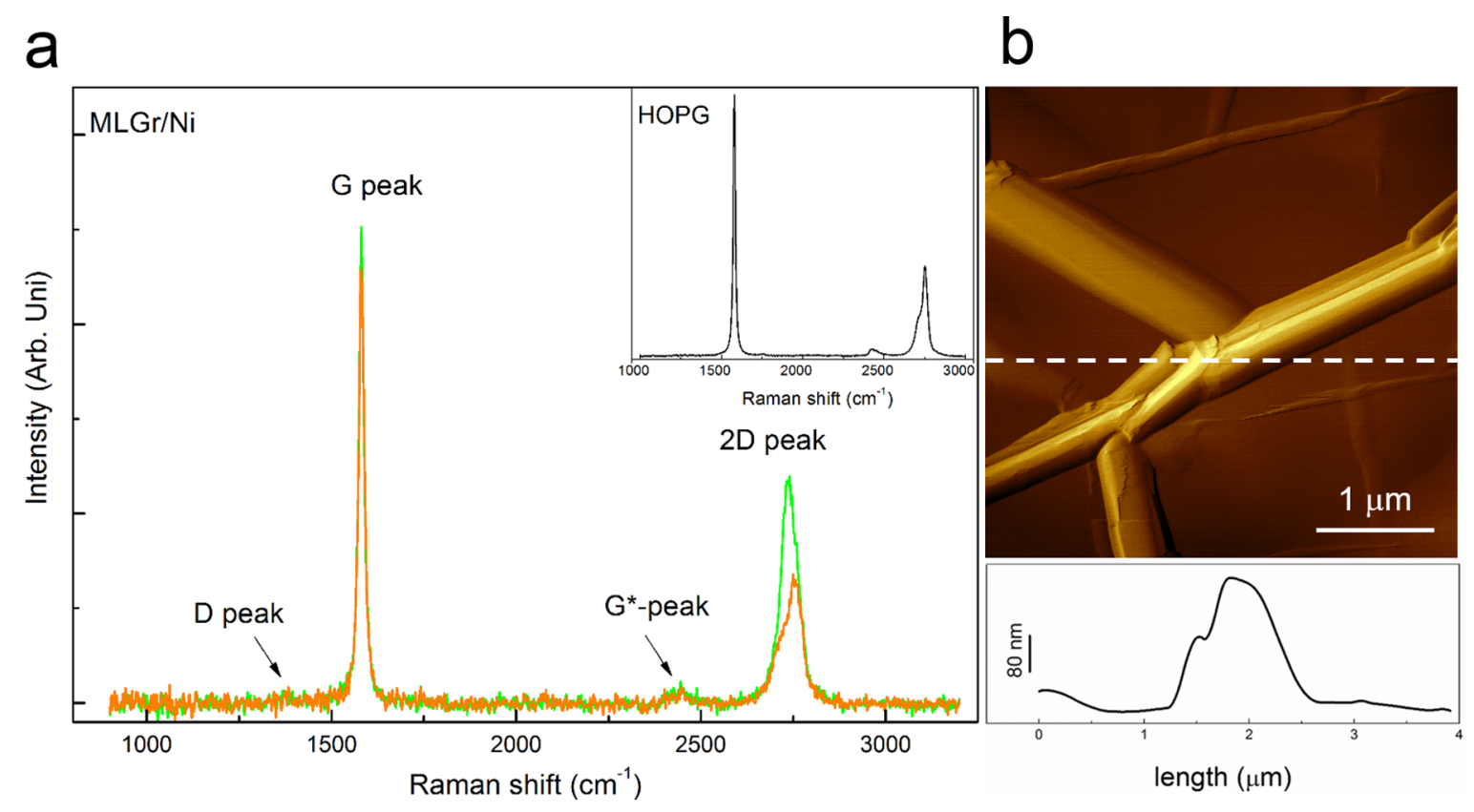

Figure 5. (a) Raman spectra acquired on two different regions of a nominally $100 \mathrm{~nm}$ thick MLGr/Ni sample. As it can be noticed by looking at the shape of the $2 \mathrm{D}$ peak, both turbostratic (green curve) and AB-stacked (orange curve) regions are present on the sample, as expected for MLGr grown on $\mathrm{Ni}^{29}$ Inset: Raman spectrum of the reference HOPG sample. Here, only AB-stacked areas are present. (b) AFM topography image $(4 \times 4$ $\mu \mathrm{m}^{2}$ ) of the MLGr/Ni sample, acquired in air and in contact mode. The scan profile of the surface (dashed line) is reported below. 

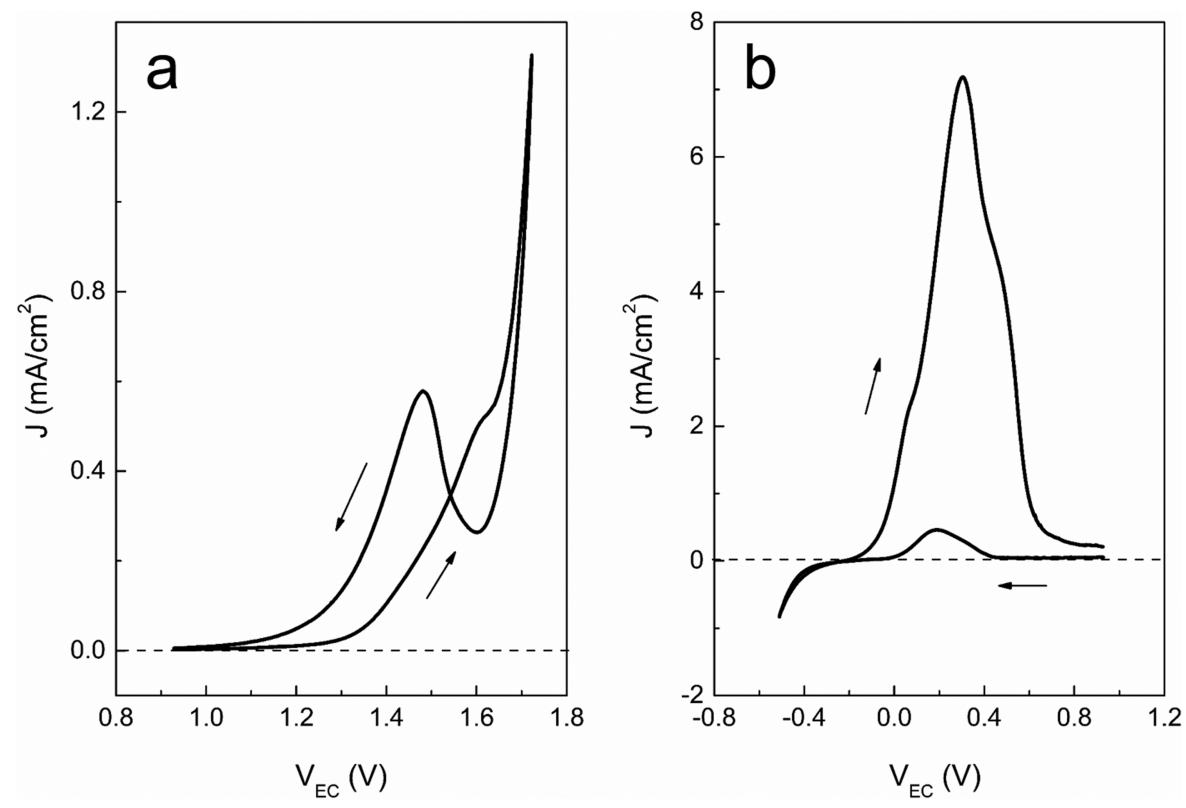

Figure 6. Voltammogram obtained on a nominally $100 \mathrm{~nm}$ thick MLGr/Ni sample in $0.5 \mathrm{M} \mathrm{H}_{2} \mathrm{SO}_{4}$, by CV in the (a) anodic region and (b) cathodic region. Scan rate $=25 \mathrm{mV} / \mathrm{s}$.

a

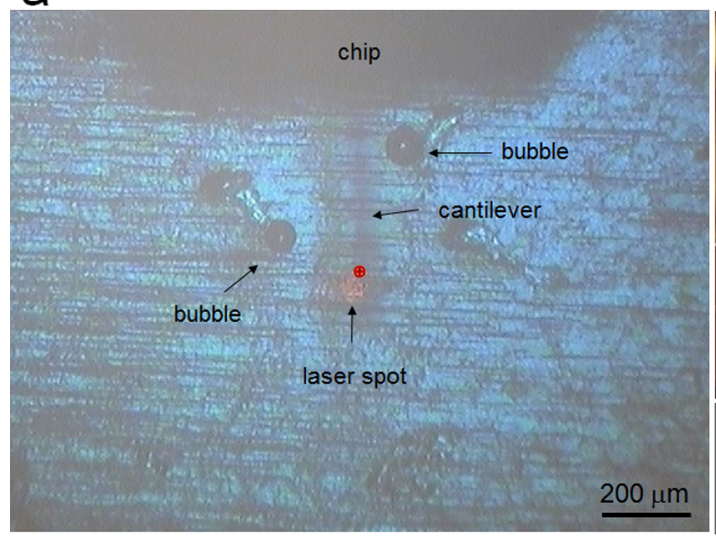

b

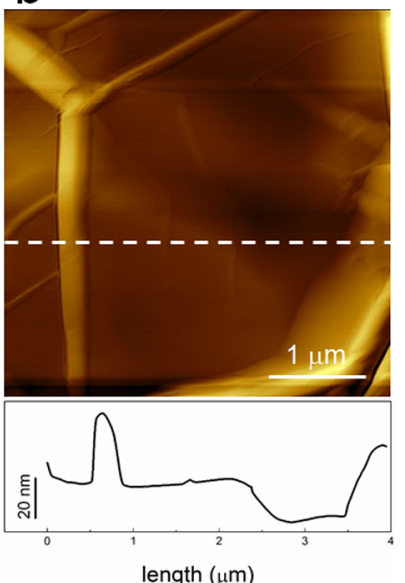

Figure 7. (a) In situ optical microscope image of a nominally $100 \mathrm{~nm}$ thick MLGr/Ni, after CV in $0.5 \mathrm{M} \mathrm{H}_{2} \mathrm{SO}_{4}$ in the anodic range (see Figure 6a). (b) AFM topography image $\left(4 \times 4 \mu \mathrm{m}^{2}\right)$ of $100 \mathrm{~nm} \mathrm{MLGr} / \mathrm{Ni}$, acquired in situ and in contact mode. The scan profile of the surface (dashed line) is reported below.

presence of these boundaries cannot be excluded a priori, but their importance must be weighted in the light of the collected microscopic images (see, for example, Figure 7). In fact, wrinkles run through the whole film, from the topmost graphene layer to the bottom most one $\mathrm{e}^{35}$ (as seen in Figure 8, by transmission electron microscopy, TEM), whereas grain boundaries within one graphene layer may not overlap with the ones in the graphene layer right below. ${ }^{4,36}$

In addition, the role of the underneath $\mathrm{Ni}$ substrate as well as the MLGr film is here supported by a methodical comparison with graphite, which results unavoidable to draw conclusions. The local surface morphology (Figure 7b), as explored by ECAFM, is similar to what previously observed on the as-prepared MLGr/Ni sample (Figure $5 b$ ). We do not observe blisters (as defined above for graphite), hence intercalation, in contrast with what was found with the HOPG electrode (Figure 2b). This is because $\mathrm{O}_{2}, \mathrm{CO}$, and $\mathrm{CO}_{2}$ gases, produced during
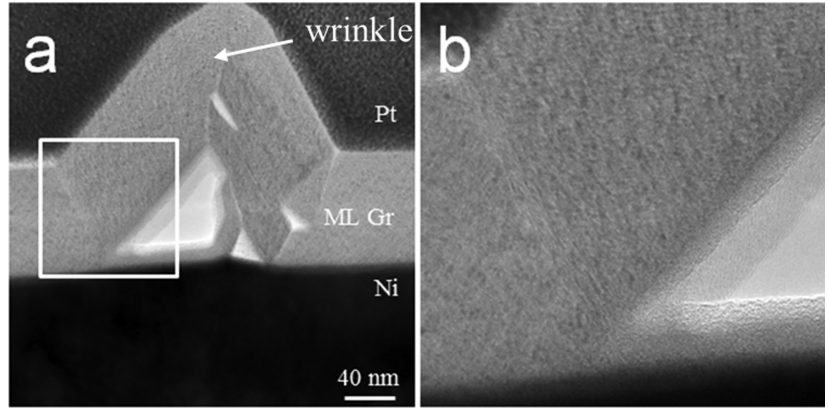

Figure 8. (a) Cross-sectional TEM $\left(320 \times 320 \mathrm{~nm}^{2}\right)$ image of the 100 $\mathrm{nm}$ thick MLGr/Ni sample. The wrinkle of the MLGr film is marked by the arrow. (b) Zoom in $\left(108 \times 108 \mathrm{~nm}^{2}\right)$ of one wrinkle edge (white square in panel a). 


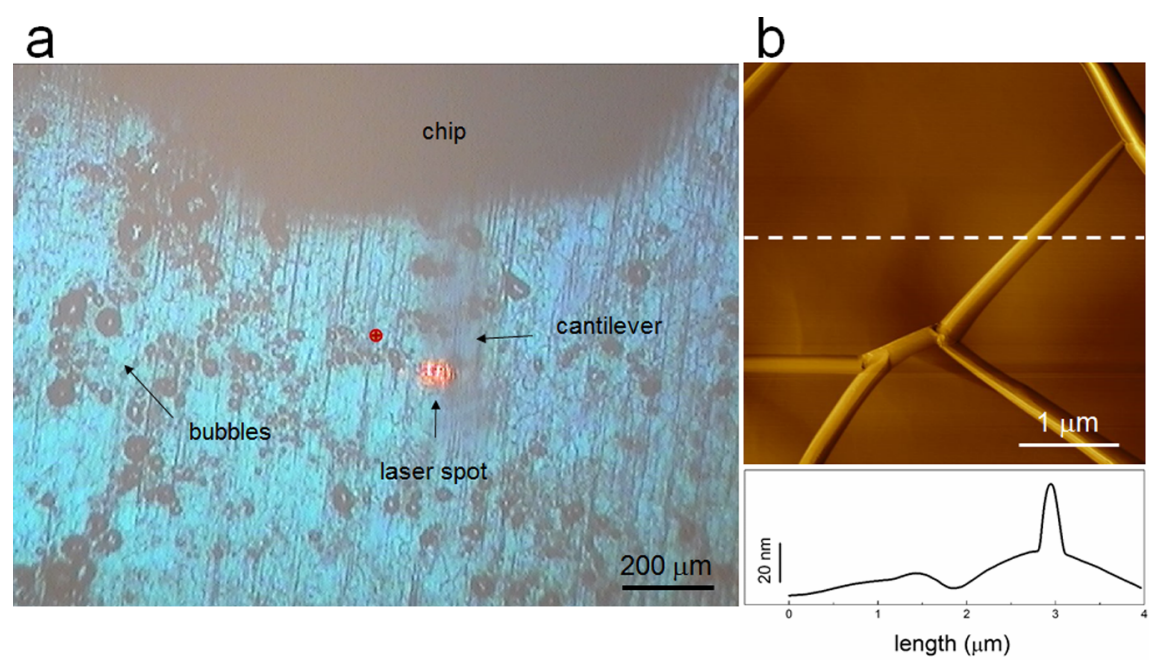

Figure 9. (a) In situ $10 \times$ optical microscope $\left(1160 \times 880 \mu \mathrm{m}^{2}\right)$ image of $100 \mathrm{~nm} \mathrm{MLGr} / \mathrm{Ni}$, after CV in $0.5 \mathrm{M} \mathrm{H}_{2} \mathrm{SO}_{4}$ in the cathodic range (see Figure 6b); (b) AFM topography image $\left(4 \times 4 \mu \mathrm{m}^{2}\right)$ of $100 \mathrm{~nm} \mathrm{MLGr} / \mathrm{Ni}$, acquired in situ and in contact mode. The scan profile of the surface (dashed line) is reported below the panel.

intercalation, $^{22}$ can thus deflate through crannies (mainly wrinkles) without any clear degradation of the Gr layers. ${ }^{31}$

The in situ optical microscopy again reveals bubbles (Figure 9a), soon after the $\mathrm{CV}$ in the cathodic regime is performed (Figure 6b), while the MLGr/Ni surface morphology (Figure $9 \mathrm{~b})$ is always comparable with the as-prepared film.

This last finding could appear to be in contradiction with recent observations of hydrogen being trapped between a MLGr film and a nickel substrate. ${ }^{11}$ In that case, droplets of 0.5 $\mathrm{M} \mathrm{H}_{2} \mathrm{SO}_{4}$ were placed on a $\mathrm{Ni}$ foil coated with MLGr film. Over time, the MLGr film would locally swell as due to buildup of hydrogen at the MLGr interface. However, the two observations are not in contradiction, because the time scale between the two experiments (i.e., the $\mathrm{CV}$ test we report here and the test with the droplet carried out in ref 11) is significantly different. In fact, when we deposit a droplet of 0.5 $\mathrm{M} \mathrm{H}_{2} \mathrm{SO}_{4}$ on our $\mathrm{ML} \mathrm{Gr} / \mathrm{Ni}$ samples and wait overnight, we can also observe swelling of the ML Gr film (see Figure 10).

To finally check the role of the Ni substrate in leading the electrochemical response of the MLGr sample, we tested other two samples with different thickness of the MLGr film. They have a half (double) thickness with respect to the one we

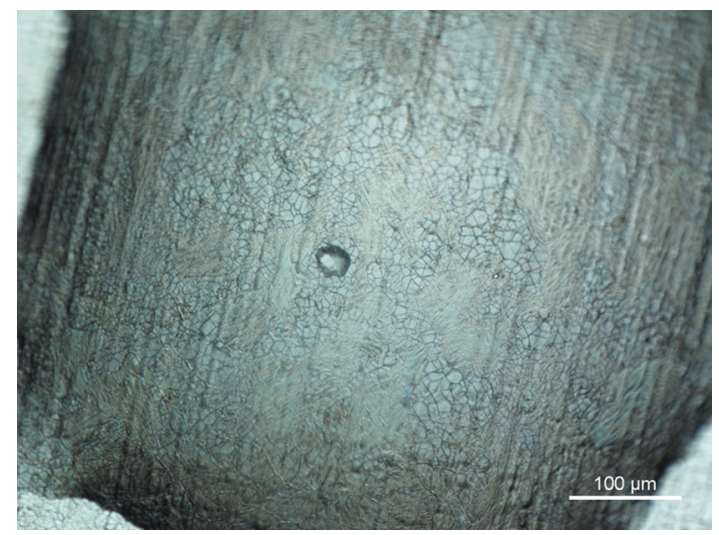

Figure 10. Optical microscope $\left(620 \times 620 \mu \mathrm{m}^{2}, 20 \times\right)$ image of 100 $\mathrm{nm} \mathrm{MLGr} / \mathrm{Ni}$. A bubble is formed on the surface, after depositing 0.5 $\mathrm{M} \mathrm{H}_{2} \mathrm{SO}_{4}$ droplet and waiting overnight. studied (i.e., 50 and $200 \mathrm{~nm}$, respectively). In comparison to the $100 \mathrm{~nm}$ sample, the acquired CV on the sample with the thinner MLGr film reveals a more intense HER feature (Figure 11a) in the cathodic region, while the voltammogram collected on the $200 \mathrm{~nm}$ thick sample (Figure 11b) shows a clear reduction of the structure at $0.35 \mathrm{~V}$ in the anodic regime.

From a morphological point of view, bubbles at the submillimeter scale are still visible on the surface of the electrode, while its local morphology is unperturbed with respect to the previous case

Our interpretation is therefore that $\mathrm{Ni}$ requires a critical MLGr thickness (not lower than $100 \mathrm{~nm}$ ) to provide a partial protective role. Despite this fact, part of the acid electrolyte can diffuse through the MLGr film and reach the buried $\mathrm{Ni}$ substrate after the sample immersion into the electrolyte. In fact, CVD Gr intrinsically does not possess the structural quality of a thick HOPG crystal, which can be thought of as an ultrathick and defect-less MLGr film. Being the Ni EC activity far larger than MLGr both in the anodic and cathodic region, significant differences are observed in the CVs of the HOPG and MLGr film of different thickness. The comparison between the three samples of different MLGr thickness (nominally, 50, $100,200 \mathrm{~nm}$ ) corroborates this interpretation. The strategy adopted in this work (i.e., direct comparison between electrochemical and microscopic data acquired on the MLGr/ $\mathrm{Ni}$ electrode with those collected on the HOPG sample) definitively attests the role of wrinkles in the MLG film on the overall electrochemical behavior of the MLGr/Ni system. This approach represents a more general successful way to interpret data (of both electrochemistry and microscopy) and could help to predict results with other carbon-like films deposited on electrodes.

To summarize, we have shown that the electrochemical behavior of the MLGr/Ni system more closely resembles that of Ni rather than that of HOPG. This might appear surprising because the electrochemical reactions happen on the electrode surface and one could reasonably think that the surface of a ML $\mathrm{Gr}$ (50-200 nm thick) on $\mathrm{Ni}$ would be very much similar to that of HOPG. From a combined CV, Raman and EC-AFM analysis together with a methodical comparison with a prototypical carbon electrode (HOPG), we find that the 

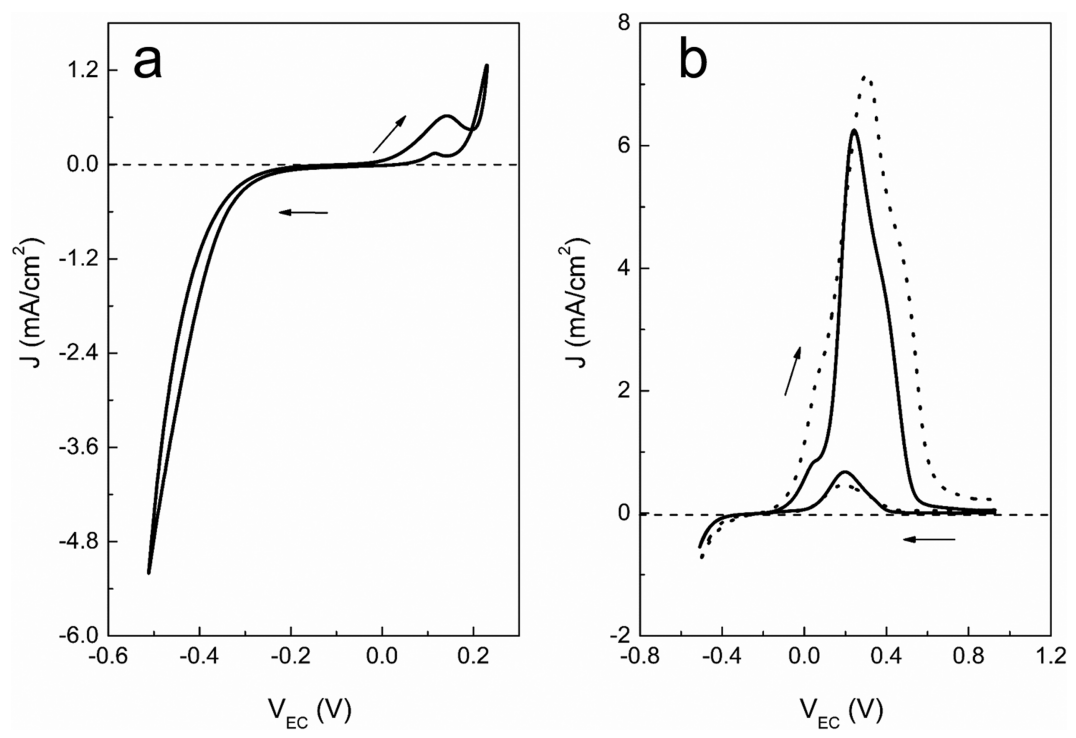

Figure 11. Voltammogram obtained by $\mathrm{CV}$ in $0.5 \mathrm{M} \mathrm{H}_{2} \mathrm{SO}_{4}$ in the cathodic range on (a) $50 \mathrm{~nm}$ MLGr/Ni sample (note that the EC potential range is the same used for the bare Ni electrode in Figure 3) and (b) $200 \mathrm{~nm} \mathrm{MLGr/Ni} \mathrm{sample} \mathrm{(continuous} \mathrm{line)} \mathrm{compared} \mathrm{with} \mathrm{the} 100 \mathrm{~nm}$ thick sample (dashed line). Scan rate $=25 \mathrm{mV} / \mathrm{s}$.

presence of wrinkles is likely to be the main reason why the MLGr/Ni sample is so highly electrochemically active and blisters are not present in the anodic brunch.

\section{EXPERIMENTAL METHODS}

The growth of graphene film on nickel was carried out as described in ref 9. Briefly, a $25 \mu \mathrm{m}$ thick nickel foil was ultrasonicated in acetone and then loaded into an AS-One (Annealsys) rapid-thermal chemical vapor deposition chamber. Next, the sample was heated at $950{ }^{\circ} \mathrm{C}$ for 15 min under the coflow of 120 and $100 \mathrm{sccm}$ of $\mathrm{Ar}$ and $\mathrm{H}_{2}$, respectively. The growth process was then performed for $150 \mathrm{~s}, 5 \mathrm{~min}$, or $10 \mathrm{~min}$ at $950{ }^{\circ} \mathrm{C}$ with $2 \mathrm{sccm} \mathrm{C}_{2} \mathrm{H}_{2}$ and $100 \mathrm{sccm} \mathrm{H}_{2}$ to obtain graphene films with 50,100, and $200 \mathrm{~nm}$ nominal thickness. Lastly, the chamber was cooled down with a rate of $20^{\circ} \mathrm{C} \mathrm{s}^{-1}$ after the pressure was pumped down below 5 mbar.

Raman spectra were collected by using a Thermo Fisher Scientific DXR Raman microscope, with a 50× objective. The excitation wavelength and the laser power used for the Raman experiments were $455 \mathrm{~nm}$ and $5.0 \mathrm{~mW}$, respectively.

A FEI Titan T20 G2 transmission electron microscope was employed for inspecting the cross-section of the MLGr/Ni electrode.

A commercial Keysight 5500 EC-AFM instrument was used in the experiments. The tip (Al coated) was driven in contact mode configuration. A single $4 \times 4 \mu \mathrm{m}^{2}$ image is acquired in few minutes. An optical microscope allows the tip positioning. The same optical microscopy set up was used for a sub-millimeter characterization of the sample in situ. A three-electrode cell with a Pt counter electrode was employed. The reference electrode was a Pt wire, ${ }^{21,37-39}$ which shows a stable difference with respect a standard hydrogen electrode. The EC cell is in Teflon and a Viton O-ring ensure the sealing of the cell.

The sulfuric acid (Sigma-Aldrich) was diluted with Type 1 water (Millipore) to obtain a $0.5 \mathrm{M}$ electrolyte solution. The latter was purified by bubbling 5.0 Ar gas for several hours.

\section{AUTHOR INFORMATION}

\section{Corresponding Author}

*E-mail: gianlorenzo.bussetti@polimi.it.

\section{ORCID}

Rossella Yivlialin: 0000-0002-6824-1519

Gianlorenzo Bussetti: 0000-0001-8556-8014

\section{Notes}

The authors declare no competing financial interest.

\section{ACKNOWLEDGMENTS}

L.C. has received funding for this project from the European Union's Horizon 2020 research and innovation programme under the Marie Sklodowska-Curie Grant Agreement No 658327. F.Y., M.G., and L.C. acknowledge the financial support from the Danish Council for Independent Research, Innovation Fund Denmark (NIAGRA, DAGATE).

\section{REFERENCES}

(1) Service, R. F. Carbon sheets an atom thick give rise to graphene dreams. Science 2009, 324, 875-877.

(2) Geim, A. K. Graphene: status and prospects. Science 2009, 324, $1530-1534$

(3) Geim, A. K.; Novoselov, K. S. The rise of graphene. Nat. Mater. 2007, 6, 183-191.

(4) Ambrosi, A.; Bonanni, A.; Sofer, Z.; Pumera, M. Large-scale quantification of CVD graphene surface coverage. Nanoscale 2013, 5 , 2379-2387.

(5) Ambrosi, A.; Chua, C. K.; Bonanni, A.; Pumera, M. Electrochemistry of graphene and related materials. Chem. Rev. 2014, 114, $7150-7188$.

(6) Dedkov, Y.; Klesse, W.; Becker, A.; Späth, F.; Papp, C.; Voloshina, E. Decoupling of graphene from Ni (111) via oxygen intercalation. Carbon 2017, 121, 10-16.

(7) Dong, A.; Fu, Q.; Wei, M.; Bao, X. Graphene-metal interaction and its effect on the interface stability under ambient conditions. Appl. Surf. Sci. 2017, 412, 262-270.

(8) Dahal, A.; Batzill, M. Graphene-nickel interface: a review. Nanoscale 2014, 6, 2548-2562.

(9) Prasai, D.; Tuberquia, J. C.; Harl, R. R.; Jennings, G. K.; Bolotin, K. I. Graphene: corrosion-inhibiting coating. ACS Nano 2012, 6 (2), $1102-1108$.

(10) Stoot, A. C.; Camilli, L.; Spiegelhauer, S.-A.; Yu, F.; Bøggild, P. Multilayer graphene for long-term corrosion protection of stainless steel bipolar plates for polymer electrolyte membrane fuel cell. J. Power Sources 2015, 293, 846-851.

(11) Yu, F.; Stoot, A. C.; Bøggild, P.; Camilli, L. Failure of multi-layer graphene coatings in acidic media. RSC Adv. 2016, 6, 21497-21502. 
(12) Ye, X. H.; Yu, F.; Curioni, M.; Lin, Z.; Zhang, H. J.; Zhu, H. W.; Liu, Z.; Zhong, M. L. Corrosion resistance of graphene directly and locally grown on bulk nickel substrate by laser irradiation. RSC Adv. 2015, 5, 35384-35390.

(13) Zhou, Y.; Chen, W.; Cui, P.; Zeng, J.; Lin, Z.; Kaxiras, E.; Zhang, Z. Enhancing the Hydrogen Activation Reactivity of Nonprecious Metal Substrates via Confined Catalysis Underneath Graphene. Nano Lett. 2016, 16, 6058-6063.

(14) Pumera, M.; Ambrosi, A.; Bonanni, A.; Chng, E. L. K.; Poh, H. L. Graphene for electrochemical sensing and biosensing. TrAC, Trends Anal. Chem. 2010, 29, 954-965.

(15) Kinoshita, K. Carbon. Electrochemical and Physicochemical Properties; John Wiley \& Sons: New York, 1988.

(16) Dresselhaus, M. S.; Endo, M. In Graphite Intercalation Compounds II; Zabel, H., Solin, S. A., Eds.; Springer-Verlag: Berlin, Heidelberg, 1992; pp 347-441.

(17) Beck, F.; Krohn, H. Reversible Electrochemical Intercalation of Anions from Aqueous Solutions in Polymer Bound Graphite Electrodes. Synth. Met. 1983, 7, 193-199.

(18) Goss, C. A.; Brumfield, J. C.; Irene, E. A.; Murray, R. W. Imaging the Incipient Electrochemical Oxidation of Highly Oriented Pyrolytic Graphite. Anal. Chem. 1993, 65, 1378-1389.

(19) Hathcock, K. W.; Brumfield, J. C.; Goss, C. A.; Irene, E. A.; Murray, R. W. Incipient Electrochemical Oxidation of Highly Oriented Pyrolytic Graphite: Correlation between Surface Blistering and Electrolyte Anion Intercalation. Anal. Chem. 1995, 67, 2201-2206.

(20) Ferrari, A. C.; Bonaccorso, F.; Fal'ko, V.; Novoselov, K. S.; Roche, S.; Bøggild, P.; Borini, S.; Koppens, F. H.; Palermo, V.; Pugno, N.; et al. Science and Technology Roadmap for Graphene, Related Two - Dimensional Crystals, and Hybrid Systems. Nanoscale 2015, 7, $4598-4610$.

(21) Alliata, D.; Kötz, R.; Haas, O.; Siegenthaler, H. In Situ AFM Study of Interlayer Spacing during Anion Intercalation into HOPG in Aqueous Electrolyte. Langmuir 1999, 15, 8483-8489.

(22) Bussetti, G.; Yivlialin, R.; Alliata, D.; Li Bassi, A.; Castiglioni, C.; Tommasini, M.; Casari, C. S.; Passoni, M.; Biagioni, P.; Ciccacci, F.; et al. Disclosing the Early Stages of Electrochemical Anion Intercalation in Graphite by a Combined Atomic Force Microscopy/ Scanning Tunneling Microscopy Approach. J. Phys. Chem. C 2016, $120,6088-6093$.

(23) Yivlialin, R.; Brambilla, L.; Bussetti, G.; Tommasini, M.; Li Bassi, A.; Casari, C. S.; Passoni, M.; Ciccacci, F.; Duò, L.; Castiglioni, C. Evolution of the Graphite Surface in Phosphoric Acid: an AFM and Raman Study. Beilstein J. Nanotechnol. 2016, 7, 1878-1884.

(24) Yivlialin, R.; Bussetti, G.; Magagnin, L.; Ciccacci, F.; Duò, L. Temporal Analysis of the Blister Evolution during Anion Intercalation in Graphite. Phys. Chem. Chem. Phys. 2017, 19, 13855-13859.

(25) vanLoon, G. W.; Duffy, S. J. Environmental Chemistry, a Global Perspective; Oxford University Press: New York, 2011.

(26) Noel, M.; Santhanam, R. Electrochemistry of graphite intercalation compounds. J. Power Sources 1998, 72, 53-65.

(27) Turner, M.; Thompson, G. E.; Brook, P. A. The Anodic Behavior of Nickel in Sulphuric Acid Solutions. Corros. Sci. 1973, 13, 985-991.

(28) Ferrari, A. C.; Meyer, J. C.; Scardaci, V.; Casiraghi, C.; Lazzeri, M.; Mauri, F.; Piscanec, S.; Jiang, D.; Novoselov, K. S.; Roth, S.; Geim, A. K. Raman Spectrum of Graphene and Graphene Layers. Phys. Rev. Lett. 2006, 97, 187401.

(29) Zhu, W.; Low, T.; Perebeinos, V.; Bol, A. B.; Zhu, Y.; Yan, H.; Tersoff, J.; Avouris, P. Structure and Electronic Transport in Graphene Wrinkles. Nano Lett. 2012, 12, 3431-3436.

(30) Tsen, A. W.; Brown, L.; Havener, R. W.; Park, J. Polycrystallinity and Stacking in CVD Graphene. Acc. Chem. Res. 2013, 46, 2286-2296.

(31) Deng, S.; Berry, V. Wrinkled, rippled and crumpled graphene: an overview of formation mechanism, electronic properties, and applications. Mater. Today 2016, 19, 197-212.

(32) Zhang, Y.; Fu, Q.; Cui, Y.; Mu, R.; Jin, L.; Bao, X. Enhanced reactivity of graphene wrinkles and their function as nanosized gas inlets for reactions under graphene. Phys. Chem. Chem. Phys. 2013, 15, 19042-19048.

(33) Zhang, Y. H.; Zhang, H. R.; Wang, B.; Chen, Z. Y.; Zhang, Y. Q.; Wang, B.; Sui, Y. P.; Zhu, B.; Tang, C. M.; Li, X. L.; Xie, X. M.; Yu, G. H.; Jin, Z.; Liu, X. Y. Role of wrinkles in the corrosion of graphene domain-coated $\mathrm{Cu}$ surfaces. Appl. Phys. Lett. 2014, 104, 143110.

(34) Bunch, J. S.; Verbridge, S. S.; Alden, J. S.; van der Zande, A. M.; Parpia, J. M.; Craighead, H. G.; McEuen, P. L. Impermeable Atomic Membranes from Graphene Sheets. Nano Lett. 2008, 8, 2458-2462.

(35) Chae, S. J.; Güneş, F.; Kim, K. K.; Kim, E. S.; Han, G. H.; Kim, S. M.; Shin, H.-J.; Yoon, S.-M.; Choi, J.-Y.; Park, M. H.; Yang, C. W.; Pribat, D.; Lee, Y. H. Synthesis of Large-Area Graphene Layers on Poly-Nickel Substrate by Chemical Vapor Deposition: Wrinkle Formation. Adv. Mater. 2009, 21, 2328-2333.

(36) Hong, J.; Lee, S.; Lee, S.; Han, H.; Mahata, C.; Yeon, H.-W.; Koo, B.; Kim, S.-I.; Nam, T.; Byun, K.; Min, B.-W.; Kim, Y.-W.; Kim, H.; Joo, Y.-C.; Lee, T. Graphene as an atomically thin barrier to $\mathrm{Cu}$ diffusion into Si. Nanoscale 2014, 6, 7503-7511.

(37) Brett, C. M. A.; Brett, A. M. O. Electrochemistry Principles, Methods, And Applications; Oxford University Press: New York, 1993.

(38) Inzelt, G. Handbook of Reference Electrodes; Springer: Berlin, 2013.

(39) Zhang, L.; Zhang, X.; Zhang, Y.; Hu, J.; Fang, H. The length scales for stable gas nanobubbles at liquid/solid surfaces. Soft Matter 2010, 6, 4515-4519. 